Check for updates

Cite this: Mater. Adv., 2021, 2, 3538

Received 8th February 2021 Accepted 2nd May 2021

DOI: 10.1039/d1ma00116g

rsc.li/materials-advances

\section{Emerging development of nanocellulose as an antimicrobial material: an overview}

\author{
Mohd Nor Faiz Norrrahim, (D) ${ }^{a}$ Norizan Mohd Nurazzi, ${ }^{\text {b }}$ Mohd Azwan Jenol, ${ }^{c}$ \\ Mohammed Abdillah Ahmad Farid, ${ }^{c}$ Nurjahirah Janudin, ${ }^{a}$ Farhana Aziz Ujang, ${ }^{a}$ \\ Tengku Arisyah Tengku Yasim-Anuar, ${ }^{d}$ Syed Umar Faruq Syed Najmuddin ${ }^{e}$ and \\ Rushdan Ahmad llyas ${ }^{\dagger}$
}

\begin{abstract}
The prolonged survival of microbes on surfaces in high-traffic/high-contact environments drives the need for a more consistent and passive form of surface sterilization to minimize the risk of infection. Due to increasing tolerance to antibiotics among microorganisms, research focusing on the discovery of naturally-occurring biocides with low-risk cytotoxicity properties has become more pressing. The latest research has centred on nanocellulosic antimicrobial materials due to their low-cost and unique features, which are potentially useful as wound dressings, drug carriers, packaging materials, filtration/adsorbents, textiles, and paint. This review discusses the latest literature on the fabrication of nanocellulose-based antimicrobial materials against viruses, bacteria, fungi, algae, and protozoa by employing variable functional groups, including aldehyde groups, quaternary ammonium, metal, metal oxide nanoparticles as well as chitosan. The problems associated with industrial manufacturing and the prospects for the advancement of nanocellulose-based antimicrobial materials are also addressed.
\end{abstract}

${ }^{a}$ Research Centre for Chemical Defence, Universiti Pertahanan Nasional Malaysia, Kem Perdana Sungai Besi, 57000 Kuala Lumpur, Malaysia.

E-mail: mohd.nurazzi@gmail.com

${ }^{b}$ Center for Defence Foundation Studies, Universiti Pertahanan Nasional Malaysia, Kem Perdana Sungai Besi, 57000 Kuala Lumpur, Malaysia

${ }^{c}$ Department of Bioprocess Technology, Faculty of Biotechnology and Biomolecular Sciences, Universiti Putra Malaysia, 43400 UPM Serdang, Selangor, Malaysia

${ }^{d}$ Nextgreen Pulp \& Paper Sdn. Bhd., Paloh Inai, 26600 Pekan, Pahang, Malaysia

${ }^{e}$ Laboratory of Vaccine and Immunotherapeutics (LIVES), Institute of Bioscience, Universiti Putra Malaysia, 43400 UPM Serdang, Selangor, Malaysia

${ }^{f}$ School of Chemical and Energy Engineering, Faculty of Engineering, Universiti Teknologi Malaysia, 81310 Skudai, Johor, Malaysia



Mohd Nor Faiz Norrrahim
Mohd Nor Faiz Norrrahim completed his PhD at the Universiti Putra Malaysia in 2018. He is now working as a postdoctoral fellow in Research Center for Chemical Defence, Universiti Pertahanan Nasional Malaysia (National Defence University of Malaysia). He has secured several awards for innovations and technology developments. His research interests include nanotechnology, nanocellulose, biocomposites and biotechnology.

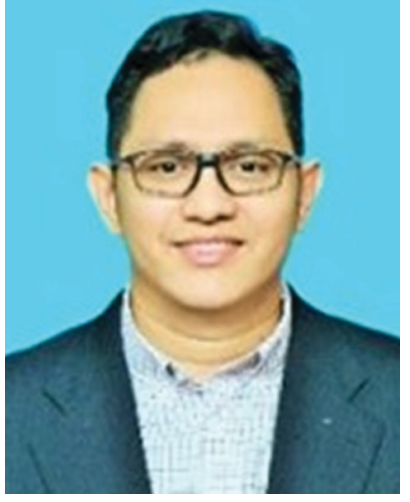

Norizan Mohd Nurazzi

N. M. Nurazzi is a Post-Doctoral Fellow at Centre for Defence Foundation Studies, National Defence University of Malaysia, under Newton Research Grant. His research interests include materials engineering, polymer composites and characterizations, natural fiber composites, graphene and carbon nanotubes for chemical sensors. He obtained a Diploma in Polymer Technology from Universiti Teknologi MARA (UiTM) in 2009, Bachelor of Science (BSc.) in Polymer Technology from Universiti Teknologi MARA (UiTM) in 2011, Master of Science (MSc) from Universiti Teknologi MARA (UiTM) in 2014 under Ministry of Higher Education Malaysia scholarship. In 2018, he was awarded a PhD from Universiti Putra Malaysia (UPM) in the field of Materials Engineering, under the Ministry of Higher Education Malaysia scholarship. 


\section{Introduction}

Infectious disease management has become an increasing challenge in recent years. According to the Centers for Disease Control and Prevention and the World Health Organization (WHO), microbial infections are a top concern. ${ }^{1}$ On December 31,2019 , the WHO reported a cluster of pneumonia cases associated with individuals who had visited a wholesale seafood and wildlife market in Wuhan City, Hubei Province, in China. ${ }^{2}$ The aetiologic agent was identified as a novel Betacoronavirus, subsequently named SARS CoV-2, and then later known as COVID-19 that rapidly spread throughout the world. ${ }^{3}$ Later on, the WHO declared the COVID-19 outbreak as a pandemic on March 12, 2020. ${ }^{4}$ COVID-19 infections keep circulating and the number of infected people continues to rise and has not shown conclusive signs of remission. During this pandemic, there are still a lot of uncertainties, especially related to its precise origin, structure, composition, suitable rapid diagnostic and immunologic tests, suitable vaccines and effective antimicrobial materials.

In ancient times, metals like copper and zinc were used to disinfect wounds. ${ }^{5}$ According to Malachova et al. (2011), ${ }^{6}$ these elements can be applied directly to the body, dissolved in aqueous solutions, or anchored to inorganic carriers from which they can be released. Infection with pathogens, particularly burn wounds, serious injuries and surgical procedures, can prolong the wound healing process. The survival and surface adherence ability of bacterial pathogens on the surface of wounds, contributing to the colonization of new hosts, contribute to the transmission of dangerous pathogens. In 2017, the WHO launched a global campaign to advance the development of antibiotics due to diminishing antibiotic effectiveness against infectious pathogens. ${ }^{7}$ The infection breakout originates from direct transmission from healthcare workers to patients, as well as via indirect interaction between the pathogens from the hospital setting and healthcare staff. ${ }^{8}$ There are about 140 known pathogens, including viruses, bacteria, and protozoa. ${ }^{9}$ Studies done by Kramer et al. $(2006)^{10}$ and Otter et al. $(2013)^{11}$ have shown that nosocomial pathogens, including Acinetobacter baumannii and Staphylococcus aureus can survive for a few weeks to months on an inanimate surface. Therefore, the acquisition of antibiotic resistance combined with passive disinfection would offer a more effective combative strategy against pathogen resiliency. Today, alternative materials bearing antimicrobial or other bioactive entities with naturally occurring low-risk cytotoxicity properties are highly sought after since they could effectively disinfect and provide infection tolerance despite recurring human physical contact. ${ }^{12}$

Nanocellulose can be a great candidate as a antimicrobial material against microbes. ${ }^{61}$ This material is well known for its versatility and excellent properties, such as having a high specific surface area, being biodegradable, renewable, allowing surface functionalization and having a high mechanical strength. ${ }^{13-20}$ According to Norrrahim et al. (2020) ${ }^{21}$ nanocellulose has been proved as one of the most effective materials that can filter several microbes. In recent years, the nanocellulose-based

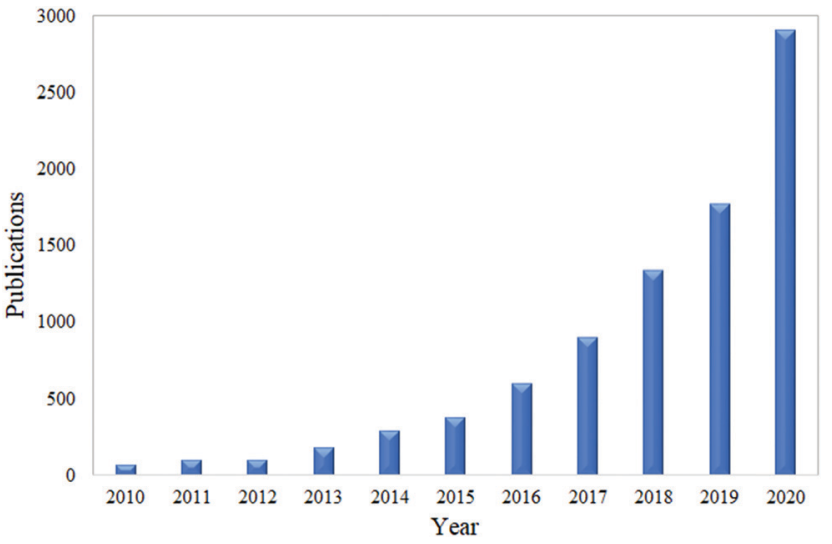

Fig. 1 Total number of publications related to nanocellulose antimicrobial material.

antimicrobial material has attracted a great deal of applications in several areas of industry. ${ }^{22}$ Based on a survey through Google Scholar using the keywords "nanocellulose as antimicrobial material", the total number of publications has shown an increasing trend over the past ten years, and this is illustrated in Fig. 1.

The nanocellulose-based antimicrobial material has great potential to be used as a component in a wide range of products. These may include protective gear (mostly in a healthcare setting), food packaging, textiles, paints, drug carriers, in ultrafiltration, as adsorbents and wound dressings. Table 1 summarizes several applications of nanocellulose as an antimicrobial material.

Therefore, this review aims to bring forward the point of the current state of research and the future development of nanocellulose as an antimicrobial material against viruses, bacteria, fungi, algae and protozoa. The use of nanocellulose is reviewed concerning the importance of its surface modifications in establishing antimicrobial nanocellulose-based materials. The important mechanism of interaction between the nanocellulose and microbes is also tackled. Last but not least, several challenges as well as future recommendations are highlighted in this review.

\section{Classification and properties of nanocellulose}

The nanocellulose structure features a diameter of 100 nanometres in one dimension and a length that may reach hundreds of micrometres or more. ${ }^{36}$ It offers a highly entangled and interconnected network structure for the scaffolding of biomaterials. This is beneficial and useful for antibiotics and the diffusion of other drugs in cell and tissue regeneration through wounds as it provides a physical shield against any infection. ${ }^{37}$

Nanocellulose is produced from cellulose, which was first extracted from a broad range of plants, animals, and bacteria. A wide variety of plant materials such as wood, oil palm biomass, bamboo, rice husk, sisal, hemp, flax, kenaf, and 
Table 1 The example of applications of nanocellulose as antimicrobial material

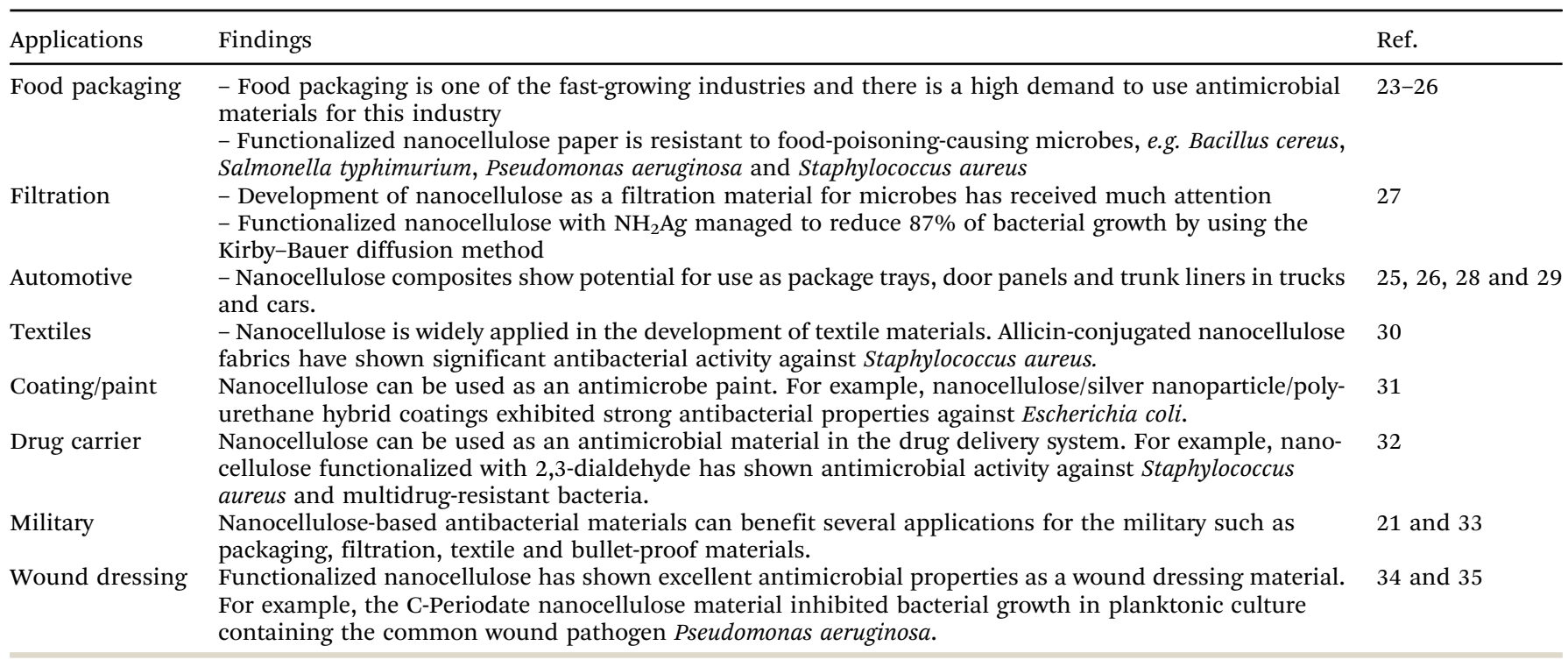

coconut husk have been studied as a source of cellulose for nanocellulose production. ${ }^{14,18,20,38-41}$ Tunicates are a type of marine invertebrate, which are a member of the subphylum Tunicata and which contain cellulose. ${ }^{39}$ There are 2300 species of tunicates and most of the research for nanocellulose production has focused on a class of tunicates commonly known as sea squirts. These tunicates produce cellulose in their outer tissue, termed tunic, from which a purified cellulose fraction named tunicin can be extracted. Otsuka et al. (2017) ${ }^{42}$ have successfully produced nanocellulose from tunicates with properties comparable to plant-based nanocellulose.

Nanocellulose can be categorized into cellulose nanofiber (CNF), cellulose nanocrystals (CNC) and bacterial nanocellulose (BNC), as shown in Fig. 2 and Table 2. Different approaches have been used to extract these three types of nanocellulose. CNF is normally produced using several methods such as mechanical, physical, and physiochemical, or by a combination thereof, while CNC can only be produced by acid pretreatment which requires strong acid hydrolysis. ${ }^{43} \mathrm{CNF}$ has long threadlike bundles of cellulose molecules stabilized laterally by hydrogen bonds between the hydroxyl groups and the oxygen atoms of adjacent molecules. ${ }^{44,45}$ Meanwhile, CNC have rod-like, highly crystalline, short structured, nanocellulose with a rectangular cross-section. Their dimensions depend on the native cellulose source material, the hydrolysis time and the temperature. $^{46}$

On the other hand, BNC is a nanocellulose produced by microorganisms. ${ }^{47}$ In contrast to $\mathrm{CNF}$ and $\mathrm{CNC}$, which may require pretreatment to remove lignin and hemicellulose before hydrolysis, BNC is synthesized as a pure cellulose material and is characterized by average diameters of 20$100 \mathrm{~nm}$ and lengths of micrometers, entangled to form stable network structures.

Nanocellulose has a similar molecular structure regardless of the source from which it was extracted (i.e. plants or bacteria). ${ }^{39}$ BNC also features high chemical purity, a high degree of polymerization, and a high degree of crystallinity, which distinguishes it from the various types of plant cellulose.

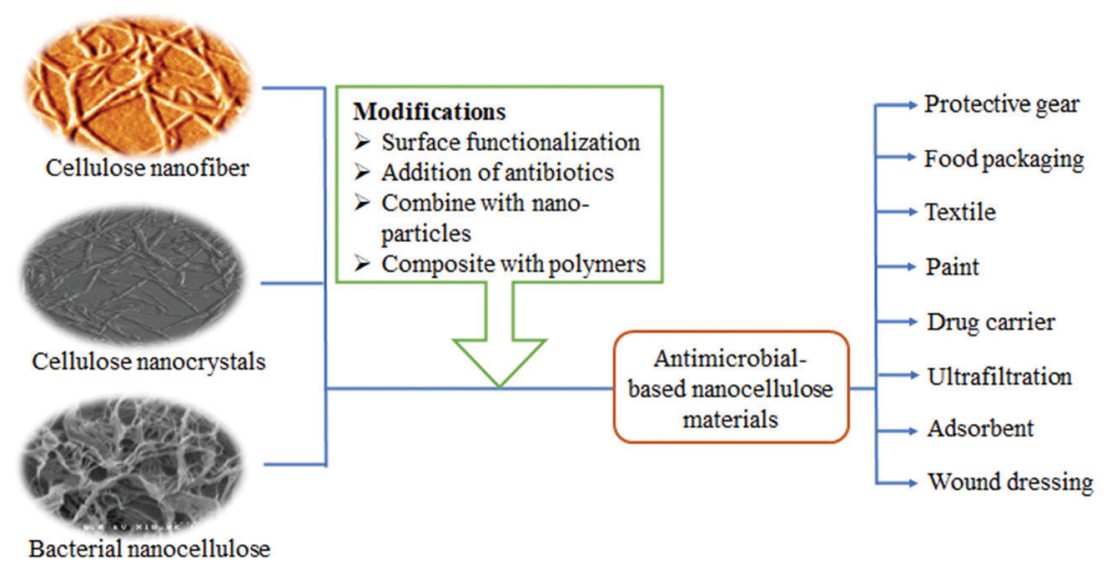

Fig. 2 Preparation and application of nanocellulose-based antimicrobial material. 
Table 2 Types of nanocellulose according to sources, treatments and dimensions

\begin{tabular}{|c|c|c|c|}
\hline Nanocellulose & Sources & Main treatments & Dimensions \\
\hline Cellulose nanofiber & Plants & Mechanical fibrillation & $\begin{array}{l}\text { Diameter: } 5-50 \mathrm{~nm} \\
\text { Length: several } \mu \mathrm{m}\end{array}$ \\
\hline Cellulose nanocrystals/nanowhiskers/nanorods & Plants & Acid hydrolysis & $\begin{array}{l}\text { Diameter: } 2-20 \mathrm{~nm} \\
\text { Length: } 100 \mathrm{~nm} \text { to several } \mu \mathrm{m}\end{array}$ \\
\hline Bacterial nanocellulose/biocellulose & Microorganisms & Polymerization and crystallization & $\begin{array}{l}\text { Diameter: } 2-4 \mathrm{~nm} \\
\text { Length: } 100 \mu \mathrm{m}\end{array}$ \\
\hline
\end{tabular}

It is of note that nanocellulose from plants is usually contaminated with hemicellulose and lignin. ${ }^{48}$ Nevertheless, the drawbacks of $\mathrm{BNC}$ are that it has a long production cycle, which can be as long as 30 days, and it is laborious but has a low yield, consequently decreasing its attractiveness among scientists. ${ }^{49}$

As shown above, there are several interesting characteristics of nanocellulose which suggest it as a suitable antimicrobial material. Table 3 summarizes the importance of these special nanocellulose characteristics, which are related to its application as an antimicrobial material.

\section{Modification of nanocellulose for antimicrobial materials}

Nanocellulose alone cannot protect human beings from developing a wound infection as it is not an antimicrobial agent. ${ }^{12}$ Over the past decade, there has been an increasing number of research teams around the world who have reported the use of nanocellulose with different antimicrobial agents. Fig. 2 shows that nanocellulose-based antimicrobial materials can be synthesized through surface modification with biocidal agents, making them effective against wound infection. ${ }^{59}$ Meanwhile, surface functionalization can be carried out through different strategies (i.e. oxidation, esterification and etherification) involving the chemistry of the hydroxyl function. ${ }^{60}$ This will allow nanocellulose to have various functional groups, including the aldehyde group and quaternary ammonium, which give them the bacteriostatic and biocompatibility properties. ${ }^{61}$ Alvarado et al. $(2019)^{59}$ and Li et al. $(2018)^{61}$ reported the identification of other cellulose conjugation agents for antimicrobial properties, including metal/ metal oxide nanoparticles (e.g. $\mathrm{Au}, \mathrm{Ag}, \mathrm{Cu}, \mathrm{CuO}, \mathrm{MgO}, \mathrm{ZnO}$, and $\mathrm{TiO}_{2}$ ), chitosan, silanes, and chlorine.

Fig. 3 shows data generated from lens.org using the search term 'functionalization of nanocellulose' and it was found that manuscripts focusing on the functionalization of nanocellulose are increasing year by year. It shows that research on the functionalization of nanocellulose has gained much interest among scientists in this decade.

Several compounds such as aldehydes, quaternary compounds (cationic and anionic), antibiotics and nanomaterials are usually added to nanocellulose. The aldehyde groups are usually grafted on nanocellulose through an oxidation process using oxidants such as periodate sodium and 2,2,6,6teramethylpiperidinyloxy (TEMPO). TEMPO can link to the surface of nanocellulose under aqueous conditions, and then the hydroxyl group at the C6 position of nanocellulose will be converted to aldehyde and carboxyl functional groups. Aldehyde-nanocellulose has been shown to have great potential in several antibacterial applications.

Besides that, quaternary compounds such as pyridinium, imidazolium and 4-vinylpyridine are the most widely used antimicrobial agents due to their antibacterial and antiviral properties. They are considered to be low toxicity and environmentally-friendly. Nanocellulose could be quaternized with these compounds through a grinding and high-pressure homogenization process. Fig. 4 illustrates an example of the functionalization of nanocellulose with several quaternary compounds for antiviral applications. Most of the viruses and some other microbe species usually contain a charge on their surface, and thus modifying the surface charge of nanocellulose will help to improve the electrostatic interaction properties.

Table 3 Several properties of nanocellulose related to its adsorbent properties

\begin{tabular}{|c|c|c|}
\hline Property & Advantages & Ref. \\
\hline Nanoporosity & $\begin{array}{l}\text { - The pore size of nanocellulose is below } 100 \mathrm{~nm} \text {, hence it can notably filter viruses, bacteria, and other } \\
\text { micro-elements } \\
\text { - It can help in cleaning water with a low back pressure while retaining a high water flux }\end{array}$ & $\begin{array}{l}14 \text { and } \\
50-52\end{array}$ \\
\hline $\begin{array}{l}\text { Surface } \\
\text { functionalization }\end{array}$ & $\begin{array}{l}\text { - Nanocellulose's binding affinity towards microbes can be enhanced by functionalising it with several } \\
\text { compounds to transform it into a charged molecule }\end{array}$ & 53 \\
\hline $\begin{array}{l}\text { High specific } \\
\text { surface area }\end{array}$ & $\begin{array}{l}\text { - Due to its nanosize, nanocellulose has a large surface area for functionalisation, which may enhance } \\
\text { the interaction efficiency }\end{array}$ & 54 \\
\hline Renewable & $\begin{array}{l}\text { - Nanocellulose can be produced from any biological waste, hence eliminating the use of non- } \\
\text { renewable materials }\end{array}$ & $\begin{array}{l}14 \text { and } \\
55\end{array}$ \\
\hline Biodegradable & $\begin{array}{l}\text { - Nanocellulose is made from renewable and biodegradable sources, and this helps in combating } \\
\text { environmental issues especially related to the disposal method }\end{array}$ & 56 \\
\hline $\begin{array}{l}\text { High mechanical } \\
\text { properties }\end{array}$ & $\begin{array}{l}\text { - Nanocellulose has higher mechanical properties compared with the original fiber. The incorporation } \\
\text { of a small amount of nanocellulose can greatly enhance the mechanical properties of many materials }\end{array}$ & 57 \\
\hline Stable in water & $\begin{array}{l}\text { - Nanocellulose is stable in water and the application of nanocellulose as a filtration material can } \\
\text { reduce the chance of biofouling }\end{array}$ & 58 \\
\hline
\end{tabular}




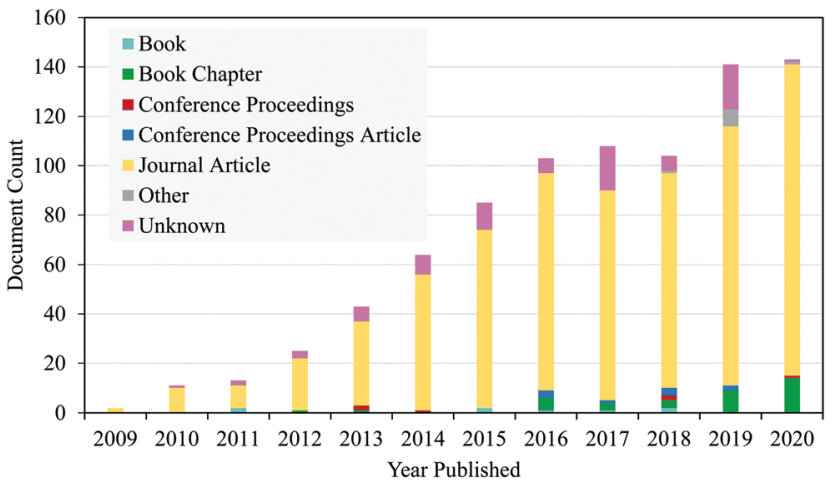

Fig. 3 A chart of published manuscripts focusing on the functionalization of nanocellulose.

This is important to produce a high-efficiency filtration material. In the next section, several interesting findings on quaternized nanocellulose for microbial removal will be discussed.

Antibiotics are usually used in the production of nanocellulose-based antibacterial materials. Table 4 shows several types of antibiotics used to fight against specific bacterial species. This approach is usually applied for packaging and biomedical application purposes. Interestingly, the consumption of antibiotics can be reduced by combining the antibiotics with nanocellulose mats or hydrogels. This could reduce the risk of antibiotic-resistant infections.

Inorganic nanoparticles such as metal nanoparticles and metal oxide nanoparticles are widely used in nanocellulosebased antimicrobial materials, especially for bacteria. They are released from the composites and are in contact with the bacteria. The minimal inhibitory concentration of inorganic nanoparticles containing nanocellulose-based materials is much lower than that of single metal or metal oxide nanoparticles, thus, showing its importance and benefits in several applications such as packaging and wound dressing.

\section{Nanocellulose as an antimicrobial material for viruses}

The ensnarement of viruses is one of the most crucial steps in biopharmaceutical and clinical applications. ${ }^{62}$ In fact, contamination by viruses is recognized to be a threat to the safety of plasma-derived biopharmaceutical products, which contributes to underscoring the need for incorporating virus contamination control strategies. ${ }^{63}$ Among several types of microbes, the virus is the smallest in size and probably the most difficult to deal with compared with other microbes. To the best of our knowledge, the development of nanocellulose-based antiviral materials is usually for filtration purposes. Size-exclusion-based virus filtration is an established, reliable and robust method to physically remove all types of infective microorganisms, including viruses. ${ }^{64}$ According to Kosiol et al. (2019), ${ }^{65}$ size-exclusion-based virus filtration has a complex internal pore network, which is capable of transmitting molecules that are smaller than $15 \mathrm{~nm}$ on a quantitative basis. Therefore, at least $99.99 \%$ of the larger microorganisms, including viruses (or the majority of relevant virus species), should be retained, mainly by size exclusion. ${ }^{66}$

The exploration of nanocellulose as a filtration material for several types of viruses has also received much attention recently. For example, the threat of the current COVID-19 pandemic is worrying as millions of people have been affected

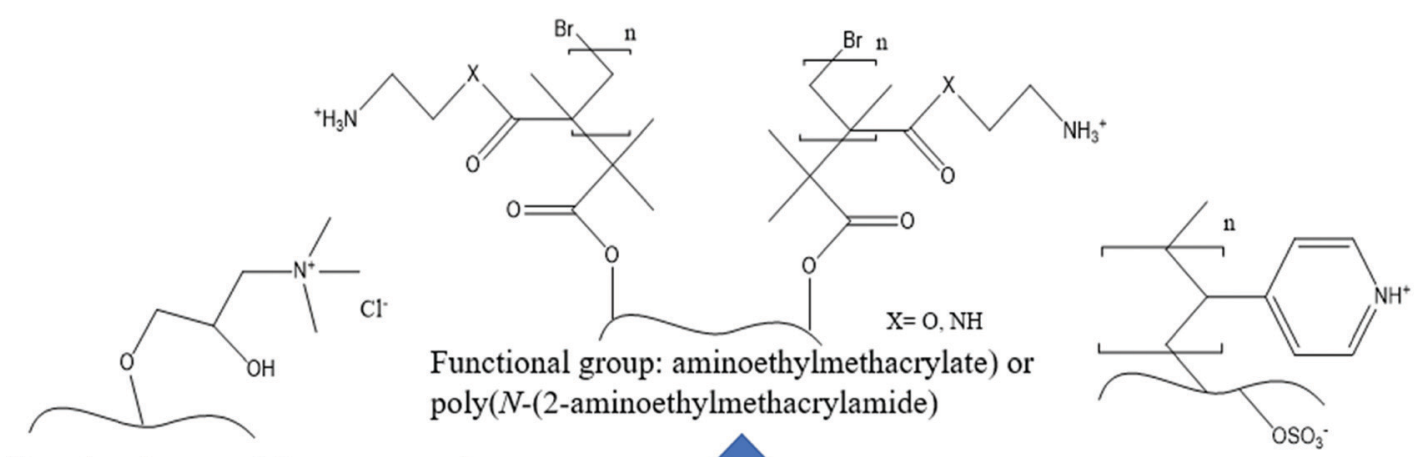

Functional group: 2,3-epoxypropyl) trimethylammonium chloride

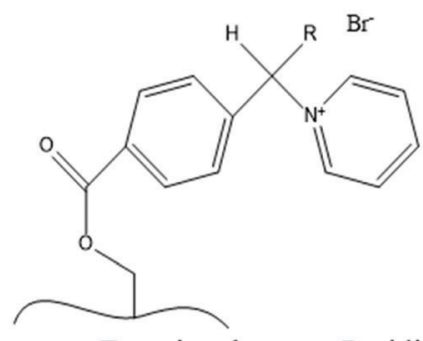

Functional group: Pyridinium

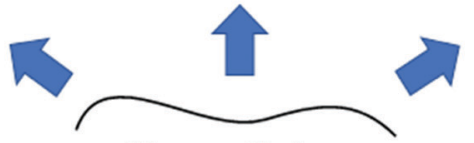

Functional group: 4-vinylpyidine

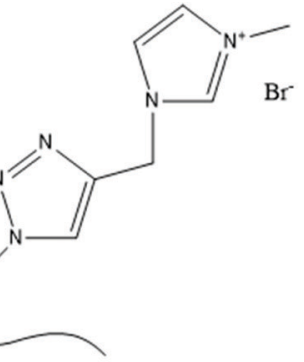

Functional group: Imidazolium

Fig. 4 Illustration of an example functionalization of nanocellulose with quaternary compounds. 
Table 4 Antibiotics and their functions in nanocellulose-based antimicrobial materials

\begin{tabular}{|c|c|}
\hline Antibiotic compound & Bacterial species \\
\hline Gentamycin & Staphylococcus aureus; Pseudomonas aeruginosa; Escherichia coli; Enterococcus faecalis \\
\hline Chloromycetin & Staphylococcus aureus; Streptococcus pneumonia; Escherichia coli \\
\hline Allicin & Staphylococcus aureus \\
\hline Polymyxin B & Pseudomonas aeruginosa; Serratia marcescens; Salmonella typhimurium; Escherichia coli; Enterobacter cloacae \\
\hline Tetracycline hydrochloride & Staphylococcus aureus; Escherichia coli \\
\hline Triclosan & Staphylococcus aureus; Escherichia coli \\
\hline Ampicillin & Staphylococcus aureus; Pseudomonas aeruginosa; Escherichia coli; Enterococcus faecalis \\
\hline Ceftriaxone & Staphylococcus aureus \\
\hline
\end{tabular}

during this outbreak. COVID-19 is an airborne virus that is spread from the human nasal or saliva secretions of an infected person. Therefore, in order to minimize the risks from this pandemic, an efficient, robust and affordable air-borne virus removal filter is in high demand for use in hospitals, transportation hubs, schools and other crowded places. There have been multiple research articles published recently regarding this aspect.

Several factors can affect the efficiency of the filtration process such as pore size, thickness, number of layers, size of the virus, charge of the filter surface, ionic strength and surface chemistry. ${ }^{50}$ In general, the benefits of using the size-exclusion filtration are: flexible and ease of use since it can provide predictable virus removal; the removal of viral markers for easy validation; and not dependence on toxic or mutagenic chemicals for inactivation. ${ }^{50,67,68}$

Metreveli et al. $(2014)^{50}$ have reported that nanocellulose filter managed to remove the Swine Influenza A Virus (SIV), which has a particle size of $80-120 \mathrm{~nm}$, as shown in Fig. 5. The latex beads and SIV particles are observed in a stacked structure on the surface of the porous filter paper.

Surface modification of nanocellulose has also been discovered to improve the filtration efficiency towards the virus. As discussed in Section 3, several quaternary compounds can be incorporated with nanocellulose to give it a cationic or anionic charge. This will improve the chemical interaction between nanocellulose and the virus. For example, the coronavirus and several other viruses are known to have a negatively charged surface. ${ }^{4}$ Fig. 6 shows the coronavirus structure with proteins embedded in the bilayer with negatively charged lipid head groups.

The electrostatic attraction between the negatively charged virus and the positively charged nanocellulose will effectively

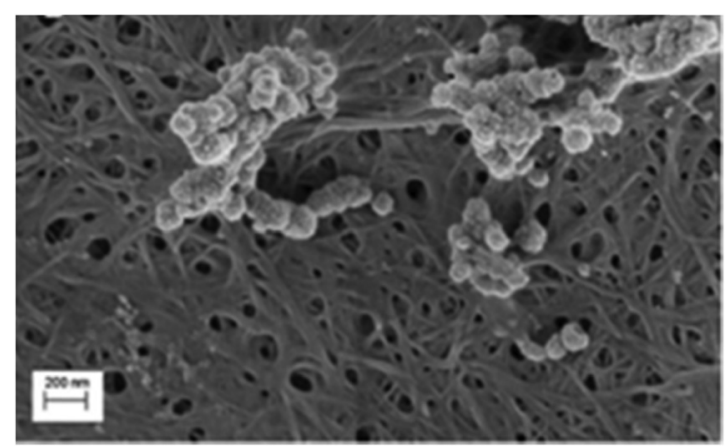

Fig. 5 SEM image of SIV filtration on a nanocellulose membrane. Copyright (2014) Wiley. Used with permission from ref. 50.



Fig. 6 Schematic representation of a coronavirus particle. Reproduced with permission from ref. 69, Future Virology, PMC, 2019

entrap the virus on the nanocellulose. The following give some examples of cationic nanocellulose developed to filter negatively charged viruses. Mi et al. $(2020)^{51}$ modified nanocellulose with a positively charged guanidine group to adsorb porcine parvovirus and Sindbis virus. The cationic nanocellulose as shown in Fig. 4 was able to completely filter the porcine parvovirus and Sindbis virus from water and exceeded the Environment Protection Agency (EPA) virus removal standard requirement for potable water. This is due to the protonated guanidine groups on the cationic nanocellulose forming ionic and hydrogen bonds with the proteins and lipids on the virus surface. ${ }^{70}$

On the other hand, Rosilo et al. (2014) ${ }^{71}$ prepared a cationic nanocellulose (known as CNC- $g$-P(QDMAEMA)s) by the surfaceinitiated atom-transfer radical polymerisation of $\operatorname{poly}\left(N, N^{-}\right.$ dimethylaminoethyl methacrylate) and subsequent quaternization of the polymer pendant amino groups as shown in Fig. 4. The addition of only a few weight percentages of this cationic nanocellulose in water dispersions was observed to efficiently bind with the cowpea chlorotic mottle virus and norovirus-like particles with high affinity.

In addition, quaternary amines were observed to have functionalization with nanocellulose as reported by Rivière et al. (2020). ${ }^{72}$ They functionalized lignin particles with quaternary amine to facilitate the removal of anionic cowpea chlorotic mottle viruses (CCMVs). In that research, they found that the CCMVs formed agglomerated complexes with the cationic lignin particles. 
Besides that, the functionalization of nanocellulose in give a negatively charged surface has also been discovered to successfully filter the EV71 virus and Sindbis. ${ }^{73}$ The modification of CNF to a negative charge was carried out by covalently modifying it with polyglutamic acid (PGA) and mesoporous silica nanoparticles (MSNs). ${ }^{73}$ Based on the aforementioned studies, the successful removal of these viruses is mainly due to the surface proteins of the viruses that contain two exposed positively charged amino acids (His10 and Lys14), which then interact with the negatively charged MSNs on the modified CNF.

Table 5 summarizes the nanocellulose-based filtration materials for virus removal. There are several other compounds, such as small organic molecules, polymers, dendrimers and porphyrin, that can be functionalized with nanocellulose to make it positively or negatively-charged. ${ }^{53}$ However, not all of these examples have been tested as a filter against viruses.

Besides that, nanocellulose has also been used as a drug carrier for certain types of antiviral compounds in medical field. For example, Acyclovir is an antiviral drug that can down-regulate herpes simplex virus (HSV) replication. HSV is typically responsible for a different form of human diseases such as herpes labialis and herpes zoster. To get the desired therapeutic effects, acyclovir has to be administered via oral or systemic route using multiple administrations of large doses, which are often plagued by significant side effects. Recently, a novel hydrogel composed of CNC, $\beta$-cyclodextrin and acrylic acid was developed for optimising the delivery of acyclovir. ${ }^{16} \mathrm{It}$ is of note that nanocellulose is mainly used as a drug carrier due to its ability to host a large number of drug molecules inside it.

To the best of our knowledge, the exploration of other applications of nanocellulose as an antiviral material have rarely been studied. Therefore, more studies are urgently needed for this research area. This is due to the recent high demand of antiviral material to be utilized in industrial products such as fabrics, packaging, and paints.

\section{Nanocellulose as an antimicrobial material for bacteria}

Similar to viruses, one of the famous applications of nanocellulose-based antimicrobial material is for filtration. Nanocellulose offers several interesting features as a filtration material for bacteria. The high specific surface area enables the adsorption of various microbial cells, and porous nanocellulose materials can separate various molecules and retain microbial objects. Several research reports have shown the effectiveness of nanocellulose as a filtration material in the removal of bacteria as shown in Table 6. The development of a nanocellulose-based filtration material can be applied in mask cartridges, water filters and air filters.

As discussed in Section 3, the modification of nanocellulose by surface functionalization is important to increase its efficiency of antibacterial properties. Compounds such as aldehydes, quaternary compounds, antibiotics and nanomaterials can be added to nanocellulose using several approaches. Table 6 also shows several functionalization approaches for nanocellulose.

Aside from bacterial filtration applications, nanocellulose is deemed as a potential material to be featured in other applications such as packaging, paper and biomedical utilities. As mentioned above, nanocellulose does not have any natural antimicrobial properties, thus it requires additional antimicrobial agents. ${ }^{32}$ Tavakolian et al. $(2020)^{32}$ suggested that the surface modification of nanocellulose is important to enhance its antibacterial properties. Besides that, the biocompatibility properties of nanocellulose make it suitable for biomedical applications.

Table 5 Nanocellulose-based filtration materials for virus removal

\begin{tabular}{|c|c|c|c|c|}
\hline Microbes & $\begin{array}{l}\text { Type of } \\
\text { nanocellulose }\end{array}$ & Functionalization & Findings & Ref. \\
\hline $\begin{array}{l}\text { A/swine/Sweden } / 9706 / 2010 \\
\text { (H1N2) - swine influenza }\end{array}$ & $\mathrm{BNC}$ & Not applicable & $\begin{array}{l}\text { - Authors developed non-woven, } \mu \text { m-thick filter paper, consisting of } \\
\text { crystalline BNC and featuring a tailored pore size distribution particularly } \\
\text { suitable for virus removal. } \\
\text { - It is capable of removing virus particles solely based on the size-exclusion } \\
\text { principle, with a log } 10 \text { reduction value of } \geq 6.3 \text {, thereby matching the } \\
\text { performance of industrial synthetic polymer virus removal filters. }\end{array}$ & 50 \\
\hline Xenotropic murine & $\mathrm{BNC}$ & Not applicable & $\begin{array}{l}\text { - The crystalline BNC filter paper is useful for the removal of endogenous } \\
\text { rodent retroviruses and retrovirus-like particles }\end{array}$ & 74 \\
\hline MS2 viruses & $\mathrm{BNC}$ & Not applicable & $\begin{array}{l}\text { - The filter exhibited } 5-6 \text { log virus clearance of } \Phi \mathrm{X} 174(28 \mathrm{~nm} \text {; pI 6.6). This } \\
\text { nanocellulose-based filter paper manufacturing process offers the possibility } \\
\text { of producing cost-efficient viral removal filters. }\end{array}$ & 64 \\
\hline Coliphages $\Phi X 174$ & $\mathrm{BNC}$ & Not applicable & $\begin{array}{l}\text { - The filter exhibited } 5-6 \log \text { virus clearance of MS2 ( } 27 \mathrm{~nm} \text {; pI 3.9). This } \\
\text { nanocellulose-based filter paper manufacturing process offers the possibility } \\
\text { of producing cost-efficient viral removal filters. }\end{array}$ & 64 \\
\hline Parvoviruses & $\mathrm{BNC}$ & Not applicable & $\begin{array}{l}\text { - The developed filter is the first non-woven, wet-laid filter paper, composed } \\
\text { of } 100 \% \text { native cellulose, which is capable of removing non-enveloped } \\
\text { parvoviruses. }\end{array}$ & 75 \\
\hline EV71 & CNF & $\begin{array}{l}\text { Polyglutamic acid } \\
\text { and mesoporous } \\
\text { silica nanoparticles }\end{array}$ & - The modified CNF strongly adsorbed the epitope of EV71 capsid. & 73 \\
\hline Sindbis virus & $\mathrm{CNC}$ & Guanidine & - Over 4 log removal value was achieved for a Sindbis virus. & 51 \\
\hline Porcine parvovirus & CNC & Guanidine & - Over 4 log removal value was achieved for a Porcine parvovirus. & 51 \\
\hline
\end{tabular}


Table 6 Nanocellulose based filtration materials for bacterial removal

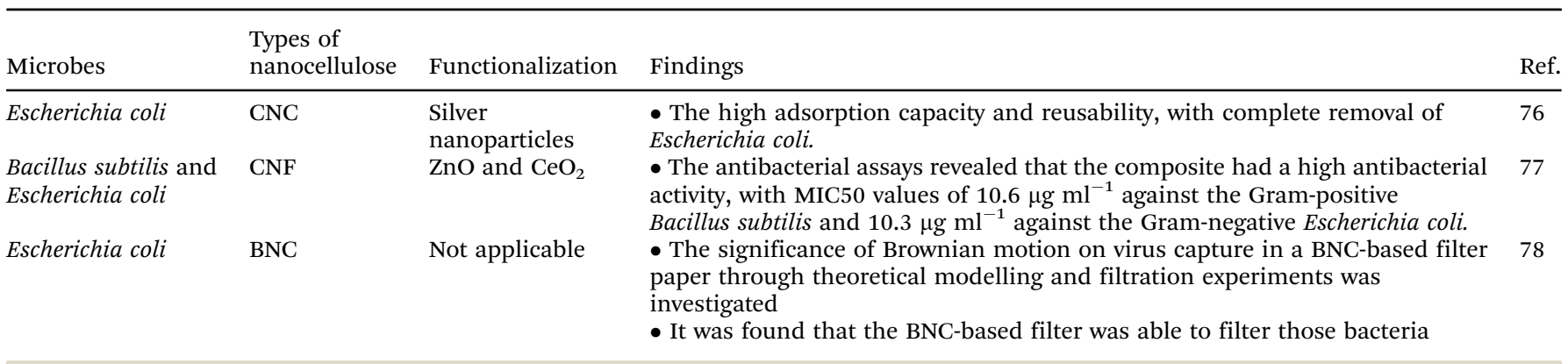

Panaitescu et al. $(2018)^{80}$ had developed a composite of poly(3-hydroxybutyrate) with nanocellulose and coated with zinc oxide $(\mathrm{ZnO})$ nanoparticles for better properties and antibacterial activity towards Escherichia coli and Staphylococcus aureus. Based on Fig. 7, ZnO plasma-treatment of nanocellulose results in the total inhibition of Staphylococcus aureus growth. Other than that, a plasma-treated nanocellulose/poly(3hydroxybutyrate) composite has been proposed as a green solution for the food packaging industry.

Moreover, Sarwar et al. $(2018)^{81}$ conducted the modification of nanocellulose to produce a nanocomposite film made of polyvinyl alcohol (PVA), nanocellulose, starch-capped Ag nanoparticles and glycerin. These nanocomposite films were processed by using casting/atmospheric evaporation intended for utilization in antimicrobial food packaging. These types of nanocomposite films have shown a strong antimicrobial property against both Gram-positive and Gram-negative bacteria; they also showed a high moisture retention capability,
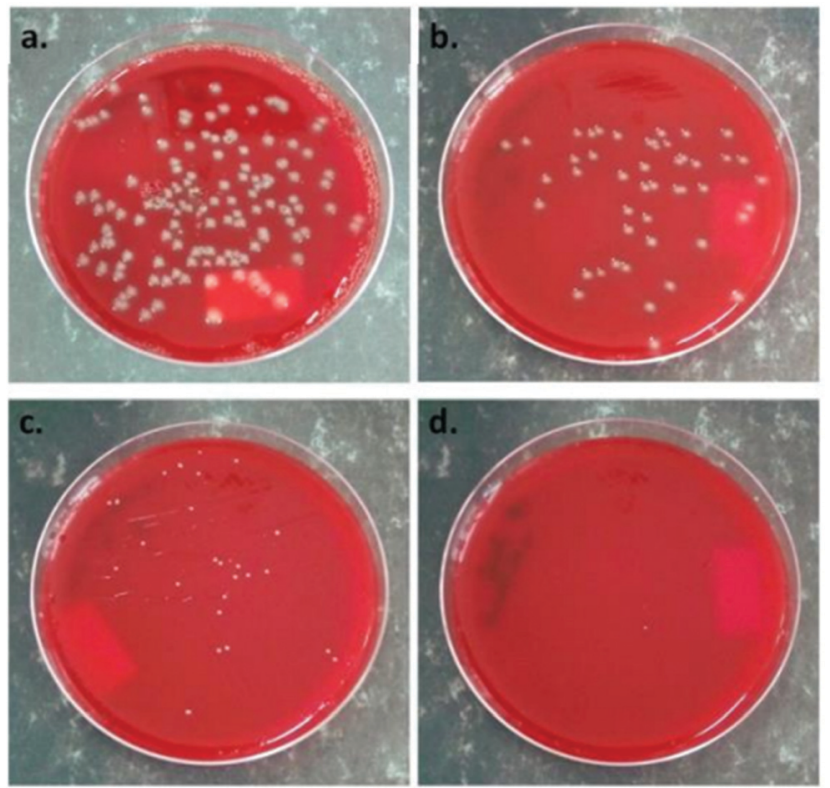

Fig. 7 Antibacterial activity of nanocellulose composite films against Escherichia coli (a) before the plasma treatment and (b) after the plasma treatment; and against Staphylococcus aureus (c) before $\mathrm{ZnO}$ plasma coating and (d) after $\mathrm{ZnO}$ plasma coating. Reproduced with permission from ref. 80, Polymers, MDPI, 2018. which further helps in retaining the freshness of fruits and vegetables.

Cationic nanocellulose compounds have an intrinsic antibacterial property since the cell walls of both Gram-positive $\left(\mathrm{G}^{+}\right)$and Gram-negative $(\mathrm{G}-)$ bacteria have a net negative charge, due to the presence of phosphate groups in the peptidoglycan and phospholipids of the outer membranes of G+ and G- bacteria, respectively. ${ }^{79}$ Tyagi et al. $(2019)^{82}$ have demonstrated the combination of CNC with chitosan for tissue coatings for antimicrobial and superabsorbent tissue papers. This modified nanocellulose can inhibit 99\% of the growth of Escherichia coli. The mechanism of this process is shown in Fig. 8(a). The developed material has a positively charged surface due to the presence of chitosan. Meanwhile, Escherichia coli has a negatively charged cell membrane. This allows the electrostatic interaction between the developed material with Escherichia coli. Besides that, the rigid and narrow CNC particles will cause damage to the cell membrane after being adsorbed on the surface of the developed material. Moreover, the accessibility of chitosan into the cell membrane will cause further damage and cause the cell membrane to denature as a result of osmotic imbalance in the cell. The combination of acetylated chitosan and CNC gave several advantages with respect to antibacterial activity. Moreover, this developed nanocellulose also has good water absorbency and high mechanical strength. The distribution of CNC in the chitosan matrix in composite is shown in Fig. 8(b). The aforementioned authors also observed that the CNC were protruding out of the surface through the chitosan matrix instead of being entrapped in the matrix. This situation has overcome the hydrophobicity characteristic of chitosan by the presence of hydrophilic CNC on the surface.

In another finding, Mou et al. (2017) ${ }^{32}$ demonstrated the modification of CNF with 2,3-dialdehyde CNF (DACNF) using sodium periodate oxidation (Fig. 9(a)). The modified DACNF is deemed to exhibit antimicrobial properties, which further help in wound healing. DACNF has antimicrobial properties against a wide variety of pathogenic bacteria, due to the acidity effect. As shown in Fig. 9(b), $\mathrm{pH}$ is the vital factor affecting the antimicrobial mechanism because it affects the activities of the protein and hydrolases in the bacterial cytomembrane, the permeability of the bacterial cytomembrane and the absorbance of nutrients. ${ }^{32}$

Besides that, Zhang et al. (2019) ${ }^{83}$ used a facile hydrothermal method for synthesizing silver (Ag) nanoparticles in 


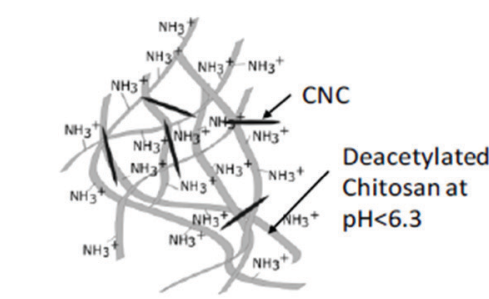

Chitosan-CNCsnetwork

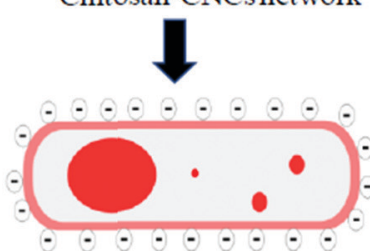

Bacterial cell with negatively charged cell-membrane



Primary interaction of cell-membrane and chitosan-CNCsnetwork

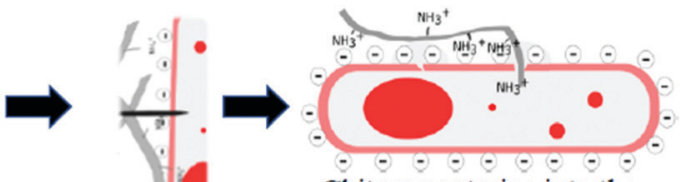

Chitosan entering into the cell and causes more damage

Rigid, narrow CNC particles causing damage to the cell membrane



Cell membrane denaturation due to osmotic imbalance in the cell

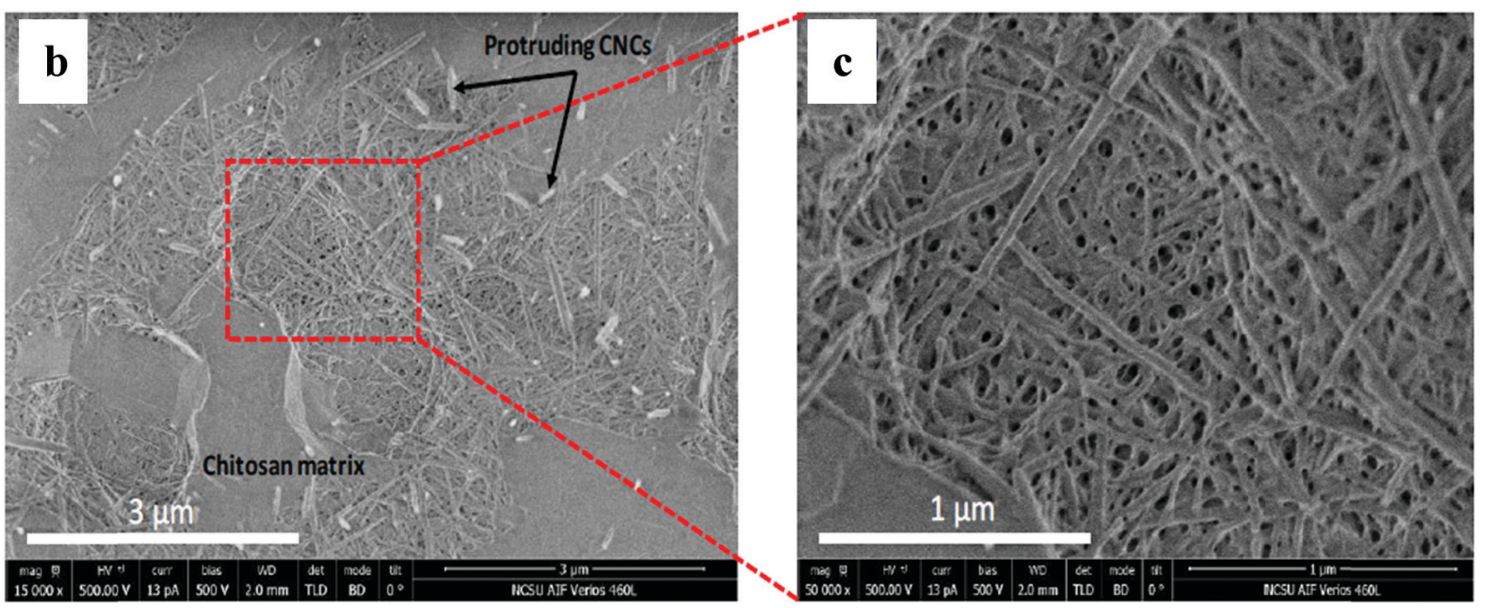

Fig. 8 (a) Schematic diagram of the theory of using nanocellulose and chitosan together for antimicrobial and superabsorbent tissue papers. The chitosan-CNC composite at different magnifications: (b) $15000 \times$ and (c) $50000 \times$. Reprinted with permission from ref. 82 . Copyright 2019 American Chemical Society.

TEMPO-oxidized nanocellulose, which acts as a reducing agent and stabilizer of the antimicrobial activity. Antibacterial tests of the nanocellulose nanocomposites were conducted with Gramnegative bacteria Escherichia coli and Gram-positive bacteria Staphylococcus aureus. The antimicrobial test results indicated that the Ag nanoparticles-nanocellulose composite has a high bactericidal efficiency towards those bacteria. This highlights its potential to be applied for the development of packaging and wound healing materials.

\section{Nanocellulose as an antimicrobial material for fungi}

Nanocellulose is a promising candidate for antimicrobial agents for fungi to attach to. This is due to the porous form and high number of reactive hydroxyl groups in their structure. ${ }^{79}$ Similar to viruses and bacteria, the modification of nanocellulose is important to improve its antifungal properties. The developed nanocellulose-based antifungal materials are useful for several applications such as in filters, packaging, paper and wound dressing.

Maliha et al. $(2020)^{84}$ have developed a paper-based renewable and biodegradable active packaging material using nanocellulose sheets with phenyl bismuth bis(diphenylphosphinato) as an additive to impart antimicrobial properties. Bismuth complexes have been reported to possess antibacterial activity. ${ }^{85-88}$ They have been used for treating intestinal disorders. Unlike other heavy metals, bismuth displays a low level of toxicity in humans and is non-carcinogenic. ${ }^{86}$ In their study, the nanocellulose sheets were prepared using a spraying technique with different loadings of phenyl bismuth bis(diphenylphosphinato). Based on the results obtained, the composite sheets displayed a good performance by inhibiting the growth of several fungi species: Schizosaccharomyces pombe, Saccharomyces cerevisiae and pathogenic Candida glabrata and Candida albicans. However, some fungal species showed a lower level of inhibition. The contamination risk is still low. 
a

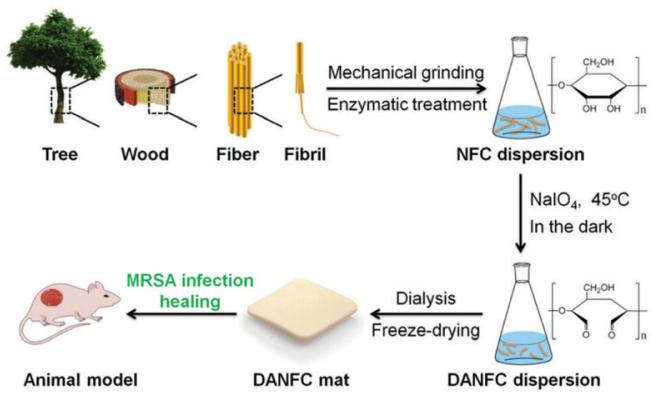

b

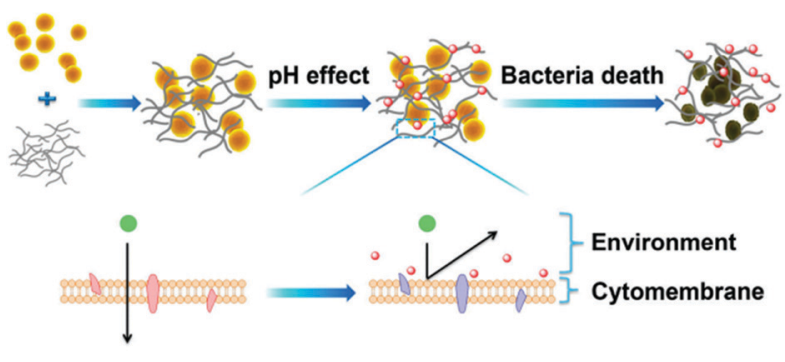

DANFC Live bacteria Dead bacteria $\circ \mathrm{H}^{+} \bullet$ Nutrient

Fig. 9 (a) Schematic diagram of the process of DACNF and wound healing, and (b) antimicrobial mechanism of DACNF. Reproduced from ref. 32 with permission from The Royal Society of Chemistry.

The use of metal-based antimicrobial agents in the form of nanoparticles or complexes has increased lately. This is due to the property of the metal, which shows good efficacy and resilience towards bacterial resistance compared with organic compounds. $^{17}$ Mocanu et al. $(2019)^{89}$ demonstrated the functionalization of BNC with zinc oxide nanoparticles ( $\mathrm{ZnO}$ NPs) and propolis extract for antimicrobial food packaging applications. ZnO NPs and propolis were used as the antimicrobial and antioxidant agents, respectively, and acted as an alternative to commercial antibiotics in order to prevent the enhancement of fungus resistance. The ZnO NPs was grown directly on the BNC via ultrasound at two frequencies (40 and $100 \mathrm{kHz}$ ), and then ethanolic propolis extract was impregnated on the BNC-ZnO at different concentrations $(3.5 \%, 7 \%, 11 \%$ and $15 \%)$. The synergic effect for antifungal activity towards Candida albicans showed that the BNC-ZnO NPs with propolis extract at an $11 \%$ concentration recorded a noticeable result with a high ultrasound frequency of $100 \mathrm{kHz}$.

Zhang et al. (2019) ${ }^{83}$ used the facile hydrothermal method in synthesizing Ag-nanoparticles in TEMPO-oxidized nanocellulose, which acts as a reducing agent and stabilizer to study the antimicrobial activity. The anti-fungus tests of the nanocellulose nanocomposites were conducted with Candida albicans. Based on Fig. 10, the antifungal results indicated that the Ag-nanoparticles-nanocellulose composite has a high fungicidal efficiency towards Candida albicans. This developed nanocellulose is deemed useful in numerous applications.

Đorđević et al. (2018) ${ }^{90}$ fabricated low-density polyethylene foil consisting of a few layers of polycaprolactone (PCL), nanocellulose and $\mathrm{CuO}$ in different compositions to improve their

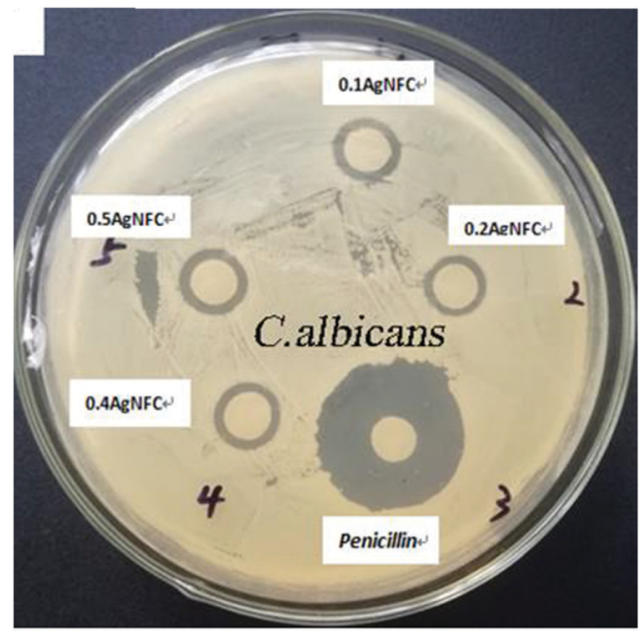

Fig. 10 The zone of inhibition results of the synthesized Ag nanoparticles in TEMPO-oxidized nanocellulose. Reprinted from ref. 83, Copyright (2019), with permission from Elsevier.

barrier and antifungal activity. The nanocellulose was modified with maleic anhydride before co-precipitating it with the $\mathrm{CuO}$, giving a nanocellulose-CuO material structure. Two types of drying methods, including conventional drying and lyophilization, were applied to determine the properties of the hybrid material. The result showed that incorporation of a $2 \%$ nanocellulose-CuO loading in PCL causes an $81.9 \%$ reduction in cell viability of Candida albicans, which indicated its excellent performance in antifungal activity. However, the drying method of lyophilisation does not contribute to improvement of the antifungal activity. This newly-developed material can be used in several applications, especially in food packaging.

Vilela et al. $(2019)^{91}$ carried out a study using a combination of poly(2-(methacryloyloxy)ethyl trimethylammonium chloride) (PMETAC) and BNC to develop antifungal nanocellulose-based composites. PMETAC is known to have antifungal activity against Candida albicans. The presence of quaternary ammonium groups in the chemical structure of the cross-linked PMETAC is expected to convert the nanocomposites into potential antifungal agents. The antifungal activity was demonstrated by a $4.4 \mathrm{log}$ reduction of Candida albicans for the nanocomposite containing only $10 \mathrm{wt} \%$ of PMETAC after $48 \mathrm{~h}$. Moreover, the in vitro cytotoxicity assay showed that the nanocomposites are non-cytotoxic towards human keratinocyte (HaCaT) cells. Hence, these bioactive and non-cytotoxic materials were considered effective to treat Candida albicans infections.

Table 7 summarizes several other developed nanocellulosebased antifungal materials.

\section{Nanocellulose as an antimicrobial material towards algae and protozoa}

Nanocellulose could also act as a removal agent for algae and protozoa, and this can be achieved by modifying it with other compounds such as metal nanoparticles, enzymes and 
Table 7 Several findings of nanocellulose as an antimicrobial material for fungus

\begin{tabular}{lll}
\hline $\begin{array}{l}\text { Type of } \\
\text { nanocellulose }\end{array}$ & Type of fungus & Functionalization \\
\hline CNF & Candida albicans & Ferulic acid and feruloylated arabinoxylo-oligosaccharides \\
Not mentioned & Candida albicans, Aspergillus niger & Allicin and lysozyme by a carbodiimide cross-linker \\
CNF & Candida albicans & Magnetic composites (iron salts of ferrous sulfate and ferric nitrate) \\
CNF & Aspergillus niger, Rhizopus stolonifer, & G. mangostana L pericarp extract \\
& Microsporum fulvum and Fusarium solani & \\
Not mentioned & Candida albicans, Aspergillus niger & Melanin(diallyl thiosulfinate) \\
Not mentioned & Aspergillus niger, Candida albicans & Polylysine and polyarginine \\
$\mathrm{CNF}$ & Saccharomyces cerevisiae & TEMPO (carboxyl), Benzalkonium chloride and copper \\
$\mathrm{CNC}$ & Saccharomyces cerevisiae & Titanium dioxide nanoparticles $\left(\mathrm{TiO}_{2}\right.$ ) \\
$\mathrm{CNC}$ & Saccharomyces cerevisiae & Oregano essential oil \\
$\mathrm{CNF}$ & Candida albicans & Thymol
\end{tabular}

proteins. Other factors, such as the membrane pore size and the charge of the nanocellulose-based membrane, could also enhance the efficiency of the removal performance. ${ }^{102}$ Studies have shown that a different charge between the membrane and algae/protozoa plays dominant role in the adsorption/retention of these microorganisms on the membrane surface (i.e. the electrostatic interaction principle). ${ }^{103,104}$

However, it is noteworthy that the number of studies regarding this issue is still lacking. Contaminated water resources can cause serious illnesses and thereby could affect human health and the environment. Algae is the major contributor to contamination in water resources and can change the taste or odour of the water. For example, certain diatoms, blue-green algae, coloured flagellates (especially Chrysophyta and Euglenophyta) as well as green algae can cause contamination of water resources. ${ }^{105}$ As a solution, the development of filtration material from nanocellulose can be explored by scientists in removing algae and protozoa from the contaminated water.

Ge et al. (2016) ${ }^{106}$ explored the sustainability and the most efficient approach to harvest microalgae using CNC. A modification was made on the $\mathrm{CNC}$ by introducing a 1-(3-aminopropyl)imidazole (APIm) structure as a reversible coagulant for harvesting the microalgae. Based on Fig. 11, the positively-charged CNC-APIm in the presence of carbon dioxide (carbonated water) could promote the coagulation of the negatively-charged Chlorella vulgaris. Their findings are in agreement with Qiu et al. $(2019)^{107}$ as a harvesting efficiency of $85 \%$ can be achieved with a $0.2 \mathrm{~g}$ CNCAPIm mass ratio, a $\mathrm{CO}_{2}$ sparging time of $5 \mathrm{~s}$ and a $50 \mathrm{ml} \mathrm{min}^{-1}$

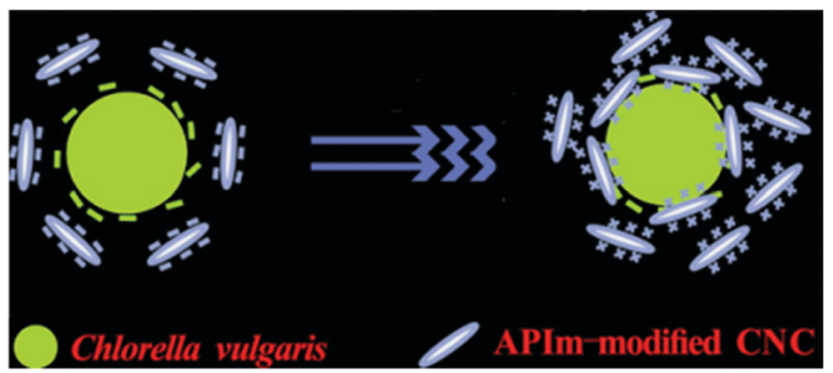

Fig. 11 Schematic illustration of the electrostatic attraction between Chlorella vulgaris and APIm-modified CNC. Reprinted with permission from ref. 106. Copyright (2016) American Chemical Society. flow rate. The CNC-APIm could be an alternative for conventional coagulants for application in the harvesting of microalgae.

\section{Challenges and future recommendations}

This review has revealed that modification of nanocellulose is undoubtedly beneficial in combating viruses, bacteria, fungi, algae, and protozoa. A study focusing on nanocellulose properties and characteristics as an antimicrobial material is a very promising and exciting area to be explored for current and future research. Several recent developments in the application of nanocellulose as an antimicrobial material were reviewed. It is interesting to note that the functionalisation of nanocellulose with a variety of functional groups is a key factor for success in enhancing the antimicrobial properties against numerous microbes.

Although the effectiveness of nanocellulose as an antimicrobial material has been demonstrated through different works, several improvements are still needed. As discussed in Section 4, the current application of nanocellulose as an antiviral material is mainly focused on filtration. Moreover, research on the use of nanocellulose-based antimicrobial materials for protozoa and algae is still very limited. Therefore, more research on these types of microbes is needed.

The functionalisation of nanocellulose is very important in order to enhance its antimicrobial properties. In this review, several compounds were shown as capable to be incorporated with nanocellulose. However, the side effects on the environment as a result of the functionalisation of nanocellulose are also important to be considered. For example, the functionalization of nanocellulose with TEMPO can have harmful effects on the environment as the synthesis of TEMPO can generate a chemical waste which is toxic to aquatic life. ${ }^{108}$ In the future, research should also be focused on determining the feasibility of the developed functionalized nanocellulose without harming the environment.

Additionally, further research is also needed to generate hybrid structures at the nanoscale on the surface of nanocellulose that is most likely to interact with different species of microbes, 
so that it is possible to develop material capable of eliminating multiple species at the same time.

Multiple challenges regarding the use of nanocellulose as an anti-microbial agent have also been identified in this review. Nanocellulose requires a high production cost, especially at the industrial level. The energy consumption related to the production of nanocellulose is still an issue hampering the scale-up production of nanocellulose. A reliable and reproducible production technique for nanocellulose is essential to pave the way for using nanocellulose as a commercial antimicrobial material. A low-energy and affordable production method to produce nanocellulose at a commercial scale should also be developed as it would diversify its usage in numerous industries. To the best of our knowledge, progress has been accomplished in this field and numerous pilot-scale productions are now available worldwide. Despite that, there is an issue regarding the biodegradability of nanocellulose. Many factors could contribute to the biodegradability of nanocellulose, such as the type of water and the presence of certain microbes that may degrade the cellulose.

Further investigation on using either CNF, CNC or BNC is also necessary to determine which kind of nanocellulose is suitable to treat different species of viruses, microbes, fungi, algae, or protozoa. This includes studies on the interaction between nanocellulose and cells, especially if the targeted application involves the incorporation of nanocellulose inside the human body. Having such information will indirectly help researchers to improve the properties of nanocellulose-based antibacterial materials. In conclusion, the use of nanocellulose as an antimicrobial material is expected to be one of the most important fields of research over the next few years to come as many researchers have realized its potential in several industries.

\section{Conflicts of interest}

There are no conflicts of interest to declare.

\section{Acknowledgements}

The authors would like to highly acknowledge financial support (UPNM/2018/CHEMDEF/ST/4) from Ministry of Education Malaysia. The authors also gratefully acknowledge Universiti Pertahanan Nasional Malaysia (National Defence University of Malaysia).

\section{References}

1 S. Mahira, A. Jain, W. Khan and A. J. Domb, Antimicrobial Materials for Biomedical Applications, Royal Society of Chemistry, 2019, pp. 1-37.

2 WHO|Pneumonia of unknown cause - China, http://www. who.int/csr/don/05-january-2020-pneumonia-of-unkown-causechina/en/, accessed 3 November 2020.

3 J. Zheng, Int. J. Biol. Sci., 2020, 16, 1678-1685.

4 W. W. F. Leung and Q. Sun, Sep. Purif. Technol., 2020, 250, 116886.
5 S. Berndt, F. Wesarg, C. Wiegand, D. Kralisch and F. A. Müller, Cellulose, 2013, 20, 771-783.

6 K. Malachová, P. Praus, Z. Rybková and O. Kozák, Appl. Clay Sci., 2011, 53, 642-645.

$7 \mathrm{WHO}$, Prioritization of pathogens to guide discovery, research and development of new antibiotics for drug-resistant bacterial infections, including tuberculosis, Geneva, Switzerland, 2017.

8 S. Schneider, B. Piening, P. A. Nouri-Pasovsky, A. C. Krüger, P. Gastmeier and S. J. S. Aghdassi, Antimicrob. Resist. Infect. Control, 2020, 9, 1-7.

9 O. Gustafsson, L. Manukyan and A. Mihranyan, Glob. Challenges, 2018, 2, 1-9.

10 A. Kramer, I. Schwebke and G. Kampf, BMC Infect. Dis., 2006, 6, 1-8.

11 J. A. Otter, S. Yezli, J. A. G. Salkeld and G. L. French, Am. J. Infect. Control, 2013, 41, S6.

12 N. Lin and A. Dufresne, Eur. Polym. J., 2014, 59, 302-325.

13 H. Ariffin, M. N. F. Norrrahim, T. A. T. Yasim-Anuar, H. Nishida, M. A. Hassan, N. A. Ibrahim and W. M. Z. W. Yunus, Bionanocomposites for Packaging Applications, Springer, 2018, pp. 95-105.

14 M. N. F. Norrahim, H. Ariffin, T. A. T. Yasim-Anuar, F. Ghaemi, M. A. Hassan, N. A. Ibrahim, J. L. H. Ngee and W. M. Z. W. Yunus, Cellulose, 2018, 25, 3853-3859.

15 M. N. F. Norrahim, H. Ariffin, T. A. T. Yasim-Anuar, M. A. Hassan, H. Nishida and T. Tsukegi, IOP Conf. Ser. Mater. Sci. Eng., 2018, 368, 1-9.

16 N. Halib, F. Perrone, M. Cemazar, B. Dapas, R. Farra, M. Abrami, G. Chiarappa, G. Forte, F. Zanconati, G. Pozzato and L. Murena, Materials, 2017, 10, 977.

17 L. Bacakova, J. Pajorova, M. Bacakova, A. Skogberg, P. Kallio, K. Kolarova and V. Svorcik, Nanomaterials, 2019, 9, 1-39.

18 T. A. T. Yasim-Anuar, H. Ariffin, M. N. F. Norrrahim, M. A. Hassan, Y. Andou, T. Tsukegi and H. Nishida, Polymers, 2020, 12, 1-17.

19 I. M. Fareez, A. H. Jasni and M. N. F. Norrrahim, Phenolic Polymers Based Composite Materials, Springer, Singapore, 2020, pp. 139-151.

20 M. N. F. Norrrahim, H. Ariffin, M. A. Hassan, N. A. Ibrahim, W. M. Z. W. Yunus and H. Nishida, Int. J. Nanotechnol., 2019, 16, 668-679.

21 M. N. F. Norrrahim, N. A. M. Kasim, V. F. Knight, F. A. Ujang, N. Janudin, M. A. I. A. Razak, N. A. A. Shah, S. A. M. Noor, S. H. Jamal, K. K. Ong and W. M. Z. W. Yunus, Mater. Adv., 2021, 2, 1485-1506, DOI: 10.1039/D0MA01011A.

22 M. N. F. Norrrahim, S. M. Sapuan, T. A. T. Yasim-Anuar, F. N. M. Padzil, N. S. Sharip, L. Y. F. Ng, L. N. Megashah, S. S. Shazleen, N. F. A. Rahim, R. Syafiq and R. A. Ilyas, Antimicrobial Studies on Food Packaging Materials, Food Packaging, 2020, pp. 141-170.

23 M. A. El-Samahy, S. A. A. Mohamed, M. H. Abdel Rehim and M. E. Mohram, Carbohydr. Polym., 2017, 168, 212-219.

24 R. Ilyas, S. Sapuan, M. N. F. Norrahim, T. A. T. YasimAnuar, A. Kadier, M. S. Kalil, M. Atikah, R. Ibrahim, 
M. Asrofi, H. Abral, A. Nazrin, R. Syafiq, H. Aisyah and M. Asyraf, Advanced Processing, Properties, and Applications of Starch and Other Bio-Based Polymers, Elsevier, 2020, pp. 65-88.

25 M. N. F. Norrrahim, T. A. T. Yasim-Anuar, M. A. Jenol, N. Mohd Nurazzi, R. A. Ilyas and S. Sapuan, Biocomposite and Synthetic Composites for Automotive Applications, 2021, pp. 119-215.

26 M. N. F. Norrahim, N. A. M. Kasim, V. F. Knight, N. A. Halim, N. A. A. Shah, S. A. M. Noor, S. H. Jamal, K. K. Ong, W. M. Z. W. Yunus, M. A. A. Farid, M. A. Jenol and R. A. Ilyas, Funct. Compos. Struct., 2021, 3, 1-17, DOI: 10.1088/2631-6331/abeef6.

27 P. Cruz-Tato, E. O. Ortiz-Quiles, K. Vega-Figueroa, L. Santiago-Martoral, M. Flynn, L. M. Díaz-Vázquez and E. Nicolau, Environ. Sci. Technol., 2017, 51, 4585-4595.

28 R. A. Ilyas, S. M. Sapuan, N. Mohd Nurazzi, M. N. F. Norrrahim, I. Rushdan, M. S. N. Atikah, M. R. M. Huzaifah, A. M. Radzi, S. Izwan, A. M. Noor Azammi, R. Jumaidin, A. Z. Mohamed and A. Atiqah, Biocomposite and Synthetic Composites for Automotive Applications, Woodhead Publishing Series, Amsterdam, Netherland, 2020, pp. 51-105.

29 R. Masoodi, R. F. El-Hajjar, K. M. Pillai and R. Sabo, Mater. Des., 2012, 36, 570-576.

30 R. Jafary, M. Khajeh Mehrizi, S. H. Hekmatimoghaddam and A. Jebali, J. Text. Inst., 2015, 106, 683-689.

31 L. Cheng, S. Ren and X. Lu, Polymers, 2020, 12, 407.

32 K. Mou, J. Li, Y. Wang, R. Cha and X. Jiang, J. Mater. Chem. B, 2017, 5, 7876-7884.

33 N. M. Nurazzi, M. R. M. Asyraf, A. Khalina, N. Abdullah, H. A. Aisyah, S. Rafiqah, F. A. Sabaruddin, S. H. Kamarudin, M. N. F. Norrrahim, R. A. Ilyas and S. M. Sapuan, Polymers, 2021, 13, 646.

34 A. Rees, L. C. Powell, G. Chinga-Carrasco, D. T. Gethin, K. Syverud, K. E. Hill and D. W. Thomas, BioMed Res. Int., 2015, 1-8.

35 N. S. Sharip, T. A. T. Yasim-Anuar, M. N. F. Norrrahim, S. S. Shazleen, N. M. Nurazzi, S. M. Sapuan and R. A. Ilyas, Composites in Biomedical Applications, CRC Press, 2020, pp. 161-190.

36 R. K. Mishra, A. Sabu and S. K. Tiwari, J. Saudi Chem. Soc., 2018, 22, 949-978.

37 K. Kupnik, M. Primožič, V. Kokol and M. Leitgeb, Polymers, 2020, 12, 1-40.

38 R. Ahmad Ilyas, S. Mohd Sapuan, R. Ibrahim, H. Abral, M. R. Ishak, E. S. Zainudin, M. Asrofi, M. Siti Nur Atikah, M. R. Muhammad Huzaifah, M. A. Radzi, A. M. Noor Azammi, M. A. Shaharuzaman, N. Mohd Nurazzi, E. Syafri, H. S. Nasmi, M. N. F. Norrrahim and R. Jumaidin, J. Mater. Res. Technol., 2019, 8, 2753-2766.

39 H. Kargarzadeh, M. Mariano, J. Huang, N. Lin, I. Ahmad, A. Dufresne and S. Thomas, Polymer, 2017, 132, 368-393.

40 M. N. F. Norrahim, T. A. T. Yasim-Anuar, S. M. Sapuan, R. A. Ilyas, M. I. Hakimi, S. U. F. S. Najmuddin and
M. A. Jenol, Bio-Based Packaging: Material, Environmental and Economic Aspects, 2021.

41 M. N. F. Norrahim, H. Ariffin, T. A. T. Yasim-Anuar, M. A. Hassan, N. A. Ibrahim, W. M. Z. W. Yunus and H. Nishida, Polymers, 2021, 13, 1064.

42 I. Otsuka, C. N. Njinang and R. Borsali, Cellulose, 2017, 24, 3281-3288.

43 L. Rueda, Carbohydr. Polym., 2013, 92, 751-757.

44 J.-H. Jang, S.-H. Lee, T. Endo and N.-H. Kim, Wood Sci. Technol., 2015, 49, 495-506.

45 M. A. S. Azizi Samir, F. Alloin and A. Dufresne, Biomacromolecules, 2005, 6, 612-626.

46 Y. Habibi, L. A. Lucia and O. J. Rojas, Chem. Rev., 2009, 110, 3479-3500.

47 T. Abitbol, A. Rivkin, Y. Cao, Y. Nevo, E. Abraham, T. BenShalom, S. Lapidot and O. Shoseyov, Curr. Opin. Biotechnol, 2016, 39, 76-88.

48 P. R. Chawla, I. B. Bajaj, S. A. Survase and R. S. Singhal, Food Technol. Biotechnol., 2009, 47, 107-124.

49 L. Y. Long, Y. X. Weng and Y. Z. Wang, Polymers, 2018, 8, 1-28.

50 G. Metreveli, L. Wågberg, E. Emmoth, S. Belák, M. Strømme and A. Mihranyan, Adv. Healthcare Mater., 2014, 3, 1546-1550.

51 X. Mi, S. M. Albukhari, C. L. Heldt and P. A. Heiden, Carbohydr. Res., 2020, 498, 108153.

52 T. A. T. Yasim-Anuar, H. Ariffin, M. N. F. Norrrahim, M. A. Hassan and T. Tsukegi, J. Cleaner Prod., 2019, 207, 590-599.

53 R. Sunasee and U. D. Hemraz, Fibers, 2018, 6, 1-19.

54 N. Lin and A. Dufresne, Nanoscale, 2012, 4, 3274-3294.

55 H. Voisin, L. Bergström, P. Liu and A. Mathew, Nanomaterials, 2017, 7, 1-19.

56 N. Mahfoudhi and S. Boufi, Cellulose, 2017, 24, 1171-1197.

57 R. Rusli and S. J. Eichhorn, Appl. Phys. Lett., 2008, 93, 1-3.

58 T. Nguyen, F. A. Roddick and L. Fan, Membranes, 2012, 2, 804-840.

59 D. R. Alvarado, D. S. Argyropoulos, F. Scholle, B. S. T. Peddinti and R. A. Ghiladi, Green Chem., 2019, 21, 3424-3435.

60 M. T. Islam, M. M. Alam and M. Zoccola, Int. J. Innov. Res. Sci., 2013, 2, 5444-5451.

61 J. Li, R. Cha, K. Mou, X. Zhao, K. Long, H. Luo, F. Zhou and X. Jiang, Adv. Healthcare Mater., 2018, 7, 1-16.

62 G. J. L. Lebrun, Rev. Environ. Sci. Bio/Technol., 2017, 16, 455-489.

63 T. Burnour and M. Radosevich, Haem, 2003, 19, 24-37.

64 L. Wu, L. Manukyan, A. Mantas and A. Mihranyan, ACS Appl. Nano Mater., 2019, 2, 6352-6359.

65 P. Kosiol, C. Kahrs, V. Thom, M. Ulbricht and B. Hansmann, Biotechnol. Prog., 2019, 35(2), e2747, DOI: 10.1002/btpr.2747.

66 S. Ray and S. Dolan, Single-Use Technology in Biopharmaceutical Manufacture, John Wiley \& Sons, 2011, pp. 311-322.

67 T. Burnouf and M. Radosevich, Haemophilia, 2003, 19, 24-37. 
68 M. Asper, T. Hanrieder, A. Quellmalz and A. Mihranyan, Biologicals, 2015, 43, 452-456.

69 E. A. J. Alsaadi and I. M. Jones, Future Virol., 2019, 14, 275-286.

70 C. Meingast and C. L. Heldt, Biotechnol. Prog., 2020, 30, 108-112.

71 H. Rosilo, J. R. McKee, E. Kontturi, T. Koho, V. P. Hytönen, O. Ikkala and M. A. Kostiainen, Nanoscale, 2014, 6, 11871-11881.

72 G. N. Rivière, A. Korpi, M. H. Sipponen, T. Zou, M. A. Kostiainen and M. Österberg, ACS Sustainable Chem. Eng., 2020, 8, 4167-4177.

73 M. Sun, H. Wang and X. Li, Mater. Lett., 2020, 277, 128320.

74 M. Asper, T. Hanrieder, A. Quellmalz and A. Mihranyan, Biologicals, 2015, 43, 452-456.

75 S. Gustafsson, P. Lordat, T. Hanrieder, M. Asper, O. Schaefer and A. Mihranyan, Mater. Horiz., 2016, 3, 320-327.

76 Suman, A. Kardam, M. Gera and V. K. Jain, Environ. Technol., 2014, 36, 706-714.

77 B. K. Nath, C. Chaliha, E. Kalita and M. C. Kalita, Carbohydr. Polym., 2016, 148, 397-405.

78 O. Gustafsson, S. Gustafsson, L. Manukyan and A. Mihranyan, Membranes, 2018, 8, 1-12.

79 M. Tavakolian, S. M. Jafari and T. G. M. van de Ven, NanoMicro Lett., 2020, 12, 1-23.

80 D. M. Panaitescu, E. R. Ionita, C. A. Nicolae, A. R. Gabor, M. D. Ionita, R. Trusca, B. E. Lixandru, I. Codita and G. Dinescu, Polymers, 2018, 10, 1-24.

81 M. S. Sarwar, M. B. K. Niazi, Z. Jahan, T. Ahmad and A. Hussain, Carbohydr. Polym., 2018, 184, 453-464.

82 P. Tyagi, R. Mathew, C. Opperman, H. Jameel, R. Gonzalez, L. Lucia, M. Hubbe and L. Pal, Langmuir, 2019, 35, 104-112.

83 X. Zhang, H. Sun, S. Tan, J. Gao, Y. Fu and Z. Liu, Inorg. Chem. Commun., 2019, 100, 44-50.

84 M. Maliha, M. Herdman, R. Brammananth, M. McDonald, R. Coppel, M. Werrett, P. Andrews and W. Batchelor, J. Cleaner Prod., 2020, 246, 119016.

85 P. Domenico, L. Baldassarri, P. E. Schoch, K. Kaehler, M. Sasatsu and B. A. Cunha, Antimicrob. Agents Chemother., 2001, 45, 1417.

86 T. Kotani, D. Nagai, K. Asahi, H. Suzuki, F. Yamao, N. Kataoka and T. Yagura, Antimicrob. Agents Chemother., 2005, 49, 2729-2734.

87 A. Luqman, V. L. Blair, R. Brammananth, P. K. Crellin, R. L. Coppel and P. C. Andrews, Eur. J. Inorg. Chem., 2016, 2738-2749.

88 M. V. Werrett, M. E. Herdman, R. Brammananth, U. Garusinghe, W. Batchelor, P. K. Crellin, R. L. Coppel and P. C. Andrews, Chem. - Eur. J., 2018, 24, 12938-12949.
89 A. Mocanu, G. Isopencu, C. Busuioc, O. M. Popa, P. Dietrich and L. Socaciu-Siebert, Sci. Rep., 2019, 9, 1-10.

90 N. Đordević, A. D. Marinković, P. Živković, D. V. Kovačević, S. Dimitrijević, V. Kokol and P. S. Uskoković, Sci. Sinter., 2018, 50, 149-161.

91 C. Vilela, H. Oliveira, A. Almeida, A. J. D. Silvestre and C. S. R. Freire, Carbohydr. Polym., 2019, 217, 207-216.

92 C. Moreirinha, C. Vilela, N. H. C. S. Silva, R. J. B. Pinto, A. Almeida, M. A. M. Rocha, E. Coelho, M. A. Coimbra, A. J. D. Silvestre and C. S. R. Freire, Food Hydrocolloids, 2020, 108, 105836.

93 A. Jebali, S. Hekmatimoghaddam, A. Behzadi, I. Rezapor, B. H. Mohammadi, T. Jasemizad, S. A. Yasini, M. Javadzadeh, A. Amiri, M. Soltani, Z. Rezaei, N. Sedighi, M. Seyfi, M. Rezaei and M. Sayadi, Cellulose, 2013, 20, 2897-2907.

94 P. K. Rahul, S. Tade, M. P. More, V. K. Chatap and P. O. Patil Deshmukh, Mater. Res. Express, 2018, 5, 116102.

95 A. Penido, P. Mendes, I. Campos and L. Mendes, Malays. J. Microbiol., 2013, 9, 166-175.

96 E. C. Estelal and R. Martínez-Máñezwer, Journal of Applied Bioscience, Medicine and Biology, 2015, 1(3), 229-242.

97 R. Bazrafshan, S. Hekmatimoghaddam and A. Jebali, Int. J. Nano Biomater., 2015, 6, 29-40.

98 M. Winans, J. Gallagher, J. Jaczynski and G. Oporto, bioRxiv, DOI: $10.1101 / 783076$.

99 N. A. El-Wakil, E. A. Hassan, R. E. Abou-Zeid and A. Dufresne, Carbohydr. Polym., 2015, 124, 337-346.

100 Y. Zhou, S. Sun, W. Bei, M. R. Zahi, Q. Yuan and H. Liang, Int. J. Biol. Macromol., 2018, 112, 7-13.

101 C. Darpentigny, P. R. Marcoux, M. Menneteau, B. Michel, F. Ricoul, B. Jean, J. Bras and G. Nonglaton, ACS Appl. Bio Mater., 2020, 3, 2965-2975.

102 D. A. Gopakumar, V. Arumughan, D. Pasquini, S. Y. Leu, H. P. S. Abdul Khalil and S. Thomas, Nanocellulose-Based Membranes for Water Purification, Elsevier Inc., 2018.

103 T. il Kim, H. Park and M. Han, KSCE J. Civ. Eng., 2017, 21, 2567-2572.

104 A. Ottenhall, J. Henschen, J. Illergård and M. Ek, Environ. Sci.: Water Res. Technol., 2018, 4, 2070-2079.

105 B. Sen, M. Tahir, F. Sonmez, M. A. Turan Kocer and O. Canpolat, Water Treatment, IntechOpen, 2013, pp. 335-354.

106 S. Ge, P. Champagne, H. Wang, P. G. Jessop and M. F. Cunningham, Environ. Sci. Technol., 2016, 50, 7896-7903.

107 S. Qiu, L. Wang, P. Champagne, G. Cao, Z. Chen, S. Wang and S. Ge, Appl. Energy, 2019, 239, 207-217.

108 S. C. Patankar and S. Renneckar, Green Chem., 2017, 19, 4792-4797. 